\title{
Single institutional experience of head and neck adenoid cystic carcinomas
}

\author{
Demircan $V^{1}$, Şahin $\mathrm{M}^{2}$, Akmansu $\mathrm{M}^{1 *}$, Aydil $\mathrm{U}^{2}$, Türkcan $\mathrm{A}^{2}$, Dikmen $\mathrm{AU}^{3}$ and Sayar $\mathrm{E}^{4}$ \\ ${ }^{1}$ Department of Radiation Oncology, Medical Faculty, Gazi University, Ankara, Turkey \\ ${ }^{2}$ Department of ENT, Medical Faculty, Gazi University, Ankara, Turkey \\ ${ }^{3}$ Department of Public Health, Medical Faculty, Gazi University, Ankara, Turkey \\ ${ }^{4}$ Department of Pathology, Medical Faculty, Gazi University, Ankara, Turkey
}

\begin{abstract}
Purpose: Aim of this study is to analyzing the outcomes of the head and neck adenoid cystic carcinomas (ACC) according to tumor stage, perineural invasion (PNI), lymphovascular invasion (LVI) and determining the risk of local failure.

Methods: The data of 68 ACC patients between 2002 and 2016 we are collected from electronic database of Gazi University Medical Faculty and patients files. Thirteen patients were excluded from study because of lack of information. Univariate Kaplan Meier and multivariate analysis Cox regression tests we are used to identify local recurrence free survival and it predictors.

Results: The mean age of study was 54.2 years. 31 patients (56.3\%) had perineural invasion, 31 patients (56.3\%) had stage T3-T4 disease and 9 patients (16.3\%) had a positive lymph node. Mean follow-up duration was 57.7 months and $73.5 \%$ of the patients survived during this period. $T$ stage of tumor ( $\mathrm{p}=0.034$ ), nodal status $(\mathrm{p}<0.001)$ and positive/close surgical margins $(\mathrm{p}=0.017)$ were determined as risk factors for disease free survival. However, in contrast to literature, postoperative radiation therapy (PORT) seemed insignificant the tumor control ( $\mathrm{p}=0.235$ ), because, all patients in the no PORT group were consisted of T1-2 tumors resected with wide surgical margins. So, the benefit of PORT could not be assessed properly due to the composition of groups.
\end{abstract}

Conclusion: There is an eloquent correlation between the local recurrence risk and T stage of tumor, nodal involvement and surgical margins. However, benefit of PORT could not be assessed properly, due to design of no PORT group.

\section{Introduction}

Adenoid cystic carcinomas (ACC) are one of the rarely seen head and neck malignancies which compose of $1 \%$ of total [1]. ACCs mostly arise from salivary gland epithelium and mucous glands of oral cavity. Despite their slow and indolent pattern of growth, ACCs are very aggressive tumors with high local recurrence and distant metastasis ratio. Surgery is the primary choice for treatment. However, results of some of the previous studies revealed that adjuvant radiotherapy increases the local control and survival rates when it is used in proper indications [2]. In this study, we want to report the outcomes of ACC of head and neck managed according to tumor stage, tumor site, positive margin, LVI, PNI and several other factors in our institution and compare the results of our series of ACC of head and neck with the literature.

\section{Materials and methods}

The data of 68 ACC patients between the 2002 and 2016 we collected from electronic database of Gazi University Medical Faculty and patients files. Thirteen patients were excluded from study because of lack of information. All the tumor sites originated from the head and neck region (major and minor salivary glands, palate, maxillary sinus, tongue) were included in the study. Only the patients who were treated with curative intent were selected. Treatment options were determined due to the $\mathrm{T}$ stage, node status and positive/close surgical margins. Neck dissection as applied to patients with T3-4 tumor or positive lymph node. Bilateral neck dissection decision as made according to tumor sites.
All the patients with T3-4 tumors, positive/close surgical margins and positive lymph node treated with adjuvant radiotherapy. Sixty Gy dose as given to the tumor bed if $\mathrm{R} 0$ (no residual disease) resection was made. If surgical margins close or positive, radiation dose as escalated up to 66-70 Gy for tumor bed. For the neck irradiation, $50 \mathrm{~Gy}$ were given to the N0 patients; 60 Gy were applied to only high risk regions. IMRT (Intensity Modulated Radiotherapy) and 3D-CRT (three dimentional conformal radiotherapy) techniques were used for radiation therapy.

Histologic subtypes, surgical margins and perineural invasion were identified by pathologic examination. Univariate Kaplan Meier analysis used to evaluate overall survival and disease free survival and multivariate Cox regression test was used to determine the significance of the risk factors for local failure.

\section{Results}

Patients' characteristics are shown in Table 1 . Seventysix percent of the patients were younger than 65 years old. Median age was 54.2.

${ }^{\star}$ Correspondence to: Muge Akmansu, Gazi University Medical Faculty Radiation Oncology Department, Ankara Turkey, Tel: +90 312202 6595; Email: akmansu@gazi.edu.tr

Key words: adenoid cystic carcinomas, radiotherapy, surgery, salivary glands, head and neck

Received: March 19, 2018; Accepted: April 05, 2018; Published: April 12, 2018 
Table 1. Patients characterictcs

\begin{tabular}{|c|c|c|c|c|}
\hline \multicolumn{2}{|c|}{ Characteristic } & \multirow{2}{*}{$\begin{array}{l}\mathbf{n} \\
42\end{array}$} & \multirow{2}{*}{$\begin{array}{c}\text { 5-year LRFS } \\
(\%)\end{array}$} & \multirow{3}{*}{$\begin{array}{r}\text { P Value } \\
0.372\end{array}$} \\
\hline \multirow{2}{*}{ Age } & $<65$ & & & \\
\hline & $>65$ & 13 & 90 & \\
\hline \multirow{2}{*}{ Gender } & Female & 26 & 84.2 & \multirow{2}{*}{0.05} \\
\hline & Male & 29 & 64.3 & \\
\hline \multirow{2}{*}{ Smoker } & No & 17 & 80.4 & \multirow{2}{*}{0.781} \\
\hline & Yes & 11 & 77.8 & \\
\hline \multirow{2}{*}{ Alcohol } & No & 7 & 64.3 & \multirow{2}{*}{0.314} \\
\hline & Yes & 38 & 74.1 & \\
\hline \multirow{5}{*}{ Site } & Submandibular & 17 & 70.7 & \multirow{5}{*}{0.619} \\
\hline & Maxilla & 9 & 50 & \\
\hline & Palate & 10 & 55.6 & \\
\hline & Parotis & 7 & 83.3 & \\
\hline & Other & 13 & 66.7 & \\
\hline \multirow{2}{*}{ Clinical T Stage } & cT1-cT2 & 24 & 94.1 & \multirow{2}{*}{0.011} \\
\hline & cT3-cT4 & 31 & 64.6 & \\
\hline \multirow{2}{*}{ Nodal status } & N1 & 9 & 21.4 & \multirow{2}{*}{$<0.001$} \\
\hline & No & 44 & 83.5 & \\
\hline \multirow{2}{*}{$\begin{array}{l}\text { Perineural } \\
\text { Invasion }\end{array}$} & No & 18 & 87.5 & \multirow{2}{*}{0.804} \\
\hline & Yes & 31 & 63.9 & \\
\hline \multirow{2}{*}{ Margins } & Negative & 20 & 80 & \multirow{2}{*}{0.017} \\
\hline & Close/positive & 26 & 56.2 & \\
\hline \multirow{2}{*}{ Tumor Size } & $\leq 4 \mathrm{~cm}$ & 25 & 89.3 & \multirow{2}{*}{0.176} \\
\hline & $>4 \mathrm{~cm}$ & 23 & 64.9 & \\
\hline \multirow{2}{*}{ PORT } & No & 15 & 87.5 & \multirow{2}{*}{0.235} \\
\hline & Yes & 40 & 68.7 & \\
\hline \multirow{2}{*}{ LVI } & Yes & 12 & 75.6 & \multirow{2}{*}{0.279} \\
\hline & No & 37 & 66.7 & \\
\hline
\end{tabular}

Male/female ratio was similar to each other, $52.7 \%$ men and $47.3 \%$ women. Only $20 \%$ of the patients were smokers, however $69 \%$ of the patients consumed mild to moderate levels of alcohol. Most of the tumors arised from the submandibular gland (30.9\%). Most of the tumors were bigger than $4 \mathrm{~cm}(41.8 \%) .12 .7$ of the patients had T1, $25.4 \%$ had $\mathrm{T} 2,21.8 \%$ had $\mathrm{T} 3$ and $34.5 \%$ of them had $\mathrm{T} 4$ tumors. Eighty percentage of the patients had N0 disease. In accordance with tumor characterstics, $56.3 \%$ of the patients had PNI. However, ratio of lymphovascular invasion was only $21.8 \%$. Relevant with big tumor sizes, most of the patients had close or positive surgical margin status (47.2\%). $72.7 \%$ of the patients received PORT as adjuvant or definitive treatment. Conformal and IMRT techniques were used for radiation therapy. Postoperative tumor site, lymph node area and pathways of mandibular and facial nerves leading to the skull base were included in the clinical target volume(CTV). Nodal status, T stage of tumor and surgical margins were independent predictors of local failure. PORT is also very effective for the local control of the disease. Local failure ratio for the PORT group was only $12.5 \%$. It is $31.3 \%$ for the no PORT group although, it seemed statistically insignificant due to the distribution of the our cohort (Figure 1).

\section{Discussion}

ACCs of head and neck are rare but aggressive tumors which are characterized by high rates of local failure, PNI and distant metastases especially in lungs [3-5]. Due to the aggressive course of the disease and adverse effects of the surgery and PORT, treatment should be performed precisely. In this regard, we aimed to report our clinical experience about ACCs, compare it with the literature and support the proper treatment modalities for selected groups of patients in order to improve quality of life. During the median follow-up time of 57.7 months $73.5 \%$ of the patients survived. Surgical margins, nodal status and $\mathrm{T}$ stage of tumor were statistically significant predictors for 5 year disease free survival according to our data (Figure 2).

In accordance with previous studies, our results seemed similar in the aspect of prognostic indicators [6-8]. However, our study and some other studies reported the perineural invasion is not related with local recurrence [9]. Also there are some studies showing that us tumor site is an important factor for prognosis [10,11]. However, in our series of ACC, tumor site is independent from the local failure of disease.

Iseli et al recently reported data of 183 ACC cases and overall survival rates for 5 and 10 years were $68.2 \%$ and $40.8 \%$ respectively [12]. They also showed the superiority of surgery+radiotherapy for disease free survival over surgey alone or radiotherapy alone. A more actual study was published by Ali et al with very favorable local control rates $89 \%$ and $79 \%$ for 5 and 10 years respectively [13]. The study supports the efficacy of PORT for local control of ACC. Despite the literature,

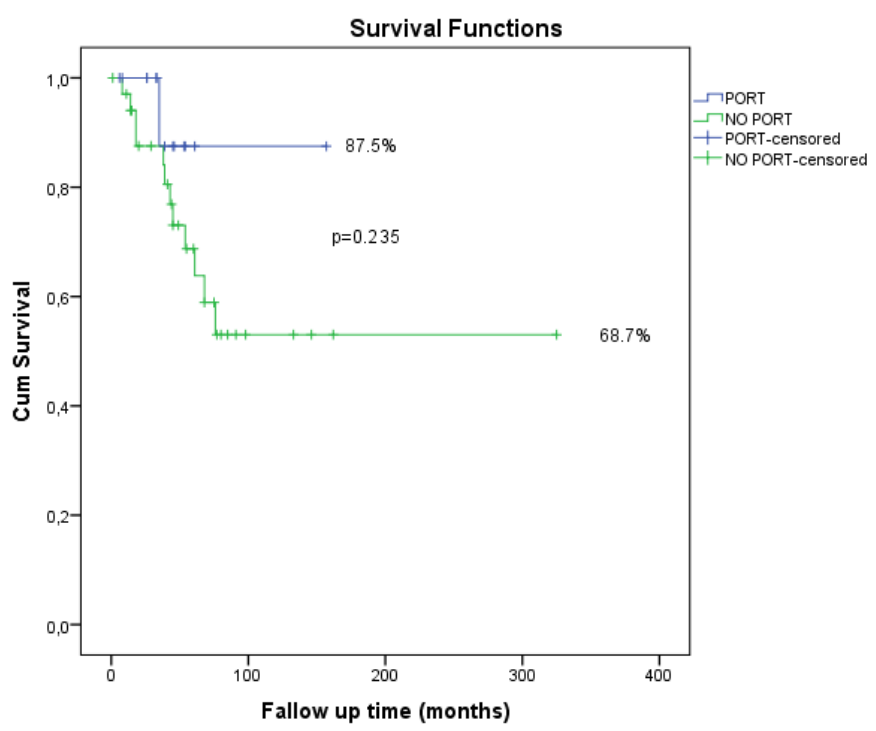

Figure 1. Graphical respretation of statistically insignificant due to the distribution of the cohort

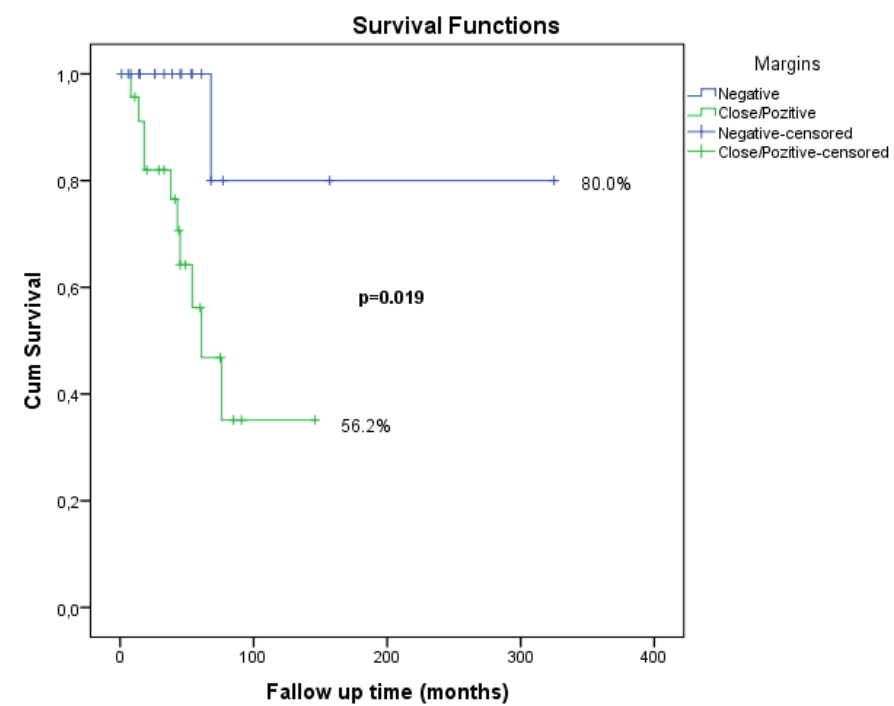

Figure 2. Graphical respretation of median follow-up time of 57.7 months $73.5 \%$ of the patients survived 
Table 2. Effects on survival with multivariete analysis

\begin{tabular}{|c|c|c|c|c|c|c|}
\hline Variable & Unadjusted HR & $95 \% \mathrm{CI}$ & P Value & Adjusted HR & $95 \% \mathrm{CI}$ & P Value \\
\hline \multicolumn{7}{|c|}{ Age } \\
\hline$<65$ & Reference & & & & & \\
\hline 65 & 3.21 & $0.98-10.47$ & 0.053 & & & \\
\hline \multicolumn{7}{|c|}{ Perineural Invasion } \\
\hline Negative & \multicolumn{2}{|l|}{ Reference } & & & & \\
\hline Positive & 1.16 & $0.36-3.66$ & 0.805 & & & \\
\hline \multicolumn{7}{|l|}{ Margins } \\
\hline Negative & \multicolumn{2}{|l|}{ Reference } & & & & \\
\hline Close/positive & 8.11 & $1.04-63.46$ & 0.046 & $5.02 *$ & $0.60-42.31$ & 0.138 \\
\hline \multicolumn{7}{|c|}{ pT Stage } \\
\hline T1T2 & \multicolumn{2}{|l|}{ Reference } & & & & \\
\hline T3T4 & 9.33 & $1.18-73.73$ & 0.034 & $3.98^{* *}$ & $0.47-33.97$ & 0.207 \\
\hline \multicolumn{7}{|c|}{ PORT } \\
\hline Yes & \multicolumn{2}{|l|}{ Reference } & & & & \\
\hline No & 3.23 & $0.42-25.16$ & 0.263 & & & \\
\hline
\end{tabular}

in our study, we could not prove the benefit of PORT for local control. Main reason of these result is the patient selection for PORT in our cohort. Also we did not have any opposite group for comparing the efficacy of PORT properly. No PORT group consisted of patients which had mostly T1 staged tumor with negative lymph nodes and wide surgical margins. So, independent of PORT, recurrence risk was already low. Nevertheless, in spite of statistical insignificance, PORT group had a higher rate of 5 years disease free survival (Table 2). However, a very newly published study, Cordesmeyer et al, analyzed the data of 61 ACC patients over a period of 21 years [14]. They found there is no difference between the surgery alone and surgery combined with PORT group for OS or DFS, even in according to T stage. These results make it compulsory to choosing the right candidates for radiotherapy.

In these regard, in the era of genomics, molecular profiling can be visualize for each patient and personalized therapies can be apply regarding to characteristics of the tumors. In one study concerned about molecular profiling, gold nanoparticles(GNP), ALK inhibitor crizotinib and radiotherapy were combined on mice experiment [15]. ALK mutated ACCs, injected to mice subcutaneously. Then radiotherapy alone or radiotherapy with ALK targeted GNP(via crizotinib coating) applied. Combined therapy significantly reduced the tumor volume compare to the radiotherapy alone. This result shows us GNPs can be use for enhancing radiotherapy. In an another study, Ferrarotto et al, detected NOTCH1 mutation in ACC related with poor prognosis [16]. A specific monoclonal antibody targeting NOTCH1 (brontictuzumab), showed a partial response in this aggressive subtype of ACC [17]. Also gamma-secretase inhibitors are effective on the solid tumors with NOTCH1 mutations [18].

Intensity modulated proton therapy(IMPT) may be another option in the treatment of ACCs for achieving to high local control rates [19]. Proton therapy make it possible to provide maximum sparing of the adjacent normal tissue while maintaining perfect coverage of the intended target [20]. According to the physical aspects of the proton beam, it gives off most of its energy at the intended target with minimal exit dose, thereby reducing the dose to the adjacent structures [21]. In addition, there is a perceived higher radiobiological effectiveness of protons compared to photon therapy due to the protons higher linear energy transfer properties and, therefore, the potentially higher cell kills [22].

\section{Conclusion}

There are some contraversies between results of the studies in the literature. However, nodal status, surgical margins and T stage of tumor were detected highly correlated with local recurrence in our study. We couldn't analyze the benefit of PORT properly, because of the absence of control group. In fact, randomized prospective studies are needed to clarify the doubts about treatment of head and neck ACCs, but rarity of disease make it difficult to proceed. In future trials we may see the effectiveness of new targeted agents and radiotherapy usage concomitantly.

\section{References}

1. Barnes LEJ, Reichart P, Sidransky D (2005) Pathology and genetics of head and neck tumours. World Health Organization Classification of Tumours. Geneva Switzerland: IARC Press.

2. Silverman DA, Carlson TP, Khuntia D, Bergstrom RT, Saxton J, et al. (2004) Role for postoperative radiation therapy in adenoid cystic carcinoma of the head and neck. Laryngoscope 114: 1194-1199. [Crossref]

3. Kim KH, Sung MW, Chung PS, Rhee CS, Park CI, et al. (1994) Adenoid cystic carcinoma of the head and neck. Arch Otolaryngol Head Neck Surg 120: 721-726. [Crossref]

4. Spiro RH (1997) Distant metastasis in adenoid cystic carcinoma of salivary origin. $\mathrm{Am}$ J Surg 174: 495-498. [Crossref]

5. Chen AM, Bucci MK, Weinberg V, Garcia J, Quivey JM, et al. (2006) Adenoid cystic carcinoma of the head and neck treated by surgery with or without postoperative radiation therapy: prognostic features of recurrence. Int J Radiat Oncol Biol Phys 66: 152-159. [Crossref]

6. Garden AS, Weber RS, Morrison WH, Ang K, Peters LJ (1995) The influence of positive margins and nerve invasion in adenoid cystic carcinoma of the head and neck treated with surgery and radiation. Int J Radiat Oncol Biol Phys 32: 619-626. [Crossref]

7. Oplatek A, Ozer E, Agrawal A, Bapna S, Schuller DE (2010) Patterns of recurrence and survival of head and neck adenoid cystic carcinoma after definitive resection. Laryngoscope 120: 65-70. [Crossref]

8. Lloyd S, Yu JB, Wilson LD, Decker RH (2011) Determinants and patterns of survival in adenoid cystic carcinoma of the head and neck, including an analysis of adjuvant radiation therapy. Am J Clin Oncol 34: 76-81. [Crossref]

9. van Weert S, Bloemena E, van der Waal I, de Bree R, Rietveld DH, et al. (2013) Adenoid cystic carcinoma of the head and neck: a single-center analysis of 105 consecutive cases over a 30-year period. Oral Oncol 49: 824-829. [Crossref]

10. Amit M, Binenbaum Y, Sharma K, Ramer N, Ramer I, et al. (2013) Adenoid cystic carcinoma of the nasal cavity and paranasal sinuses: a meta-analysis. $J$ Neurol Surg $B$ Skull Base 74: 118-125. [Crossref]

11. Ellington CL, Goodman M, Kono SA, Grist W, Wadsworth T, et al. (2012) Adenoid cystic carcinoma of the head and neck: incidence and survival trends based on 19732007. Surveillance, epidemiology, and end results data. Cancer 118: 4444-4451. [Crossref]

12. Iseli TA, Karnell LH, Graham SM, Funk GF, Buatti JM, et al. (2009) Role of radiotherapy in adenoid cystic carcinoma of the head and neck. J Laryngol Otol 123: 1137-1144. [Crossref] 
13. Ali S, Palmer FL, Katabi N, Lee N, Shah JP, et al. (2017) Long-Term Local Control Rates of Patients With Adenoid Cystic Carcinoma of the Head and Neck Managed by Surgery and Postoperative Radiation. Laryngoscope 127: 2265-2269. [Crossref]

14. Cordesmeyer R, Schliephake H, Kauffmann P, Tröltzsch M, Laskawi R, et al. Clinical prognostic factors of salivary adenoid cystic carcinoma: A single-center analysis of 61 patients. J Craniomaxillofac Surg 4: 1784-1787. [Crossref]

15. Hazkani I, Motiei M, Betzer O, Sadan T, Bragilovski D, et al. (2017) Can molecular profiling enhance radiotherapy? Impact of personalized targeted gold nanoparticles on radiosensitivity and imaging of adenoid cystic carcinoma. Theranostics 7: 3962-3971. [Crossref]

16. Ferrarotto R, Heymach JV, Glisson BS (2016) MYB-fusions and other potential actionable targets in adenoid cystic carcinoma. Curr Opin Oncol 28:1 95-200. [Crossref]

17. Ferrarotto R, Mitani Y, Diao L, Guijarro I, Wang J, et al. (2017) Activating NOTCH1 Mutations Define a Distinct Subgroup of Patients with Adenoid Cystic Carcinoma
Who Have Poor Prognosis, Propensity to Bone and Liver Metastasis, and Potential Responsiveness to Notch1 Inhibitors. J Clin Oncol 35: 352-360. [Crossref]

18. Stoeck A, Lejnine S, Truong A, Pan L, Wang H, et al. (2014) Discovery of biomarkers predictive of GSI response in triple-negative breast cancer and adenoid cystic carcinoma. Cancer Discov 4: 115411-67. [Crossref]

19. Phan J, Ping Ng S, Pollard C, Phan J (2017) A Rare Case of Unresectable Adenoid Cystic Carcinoma of the Nasopharynx Treated with Intensity Modulated Proton Therapy. Cureus 9: e1688. [Crossref]

20. Frank SJ (2016) Intensity modulated proton therapy for head and neck tumors: gilding the lily or holy grail? Int J Radiat Oncol Biol Phys 95: 37-39. [Crossref]

21. Frank SJ, Selek U (2010) Proton beam radiation therapy for head and neck malignancies. Curr Oncol Rep 12: 202-207. [Crossref]

22. Hall EJ (2000) Radiobiology for the Radiologist. (5th edn), Lippincott Williams \& Wilkins, Philadelphia, PA, USA.

Copyright: $₫ 2018$ Demircan V. This is an open-access article distributed under the terms of the Creative Commons Attribution License, which permits unrestricted use, distribution, and reproduction in any medium, provided the original author and source are credited. 